\title{
Die noodsaak om lyding, pyn, dood en boosheid tot betekenis te bring
}

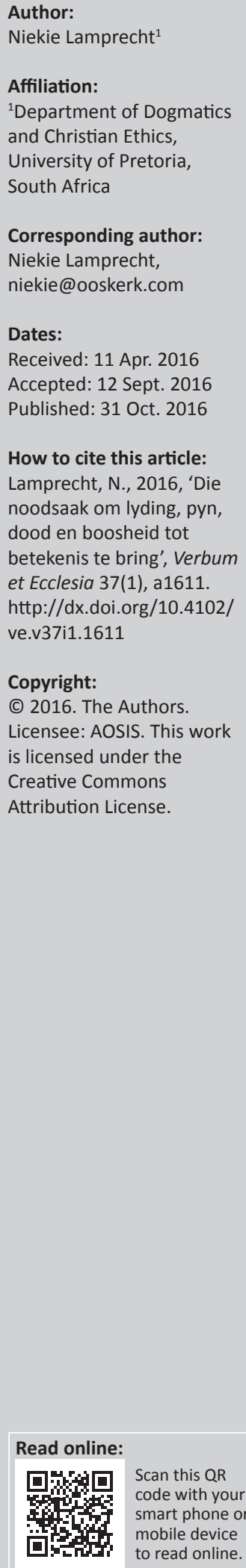

\begin{abstract}
To make sense of suffering was always part and parcel of being human. Although the inadequacy of theodicies to provide meaningful theoretical frameworks resulted in a focus on practical responses, in this article a case has been made for the necessity to create theoretical meaning frameworks to make sense of suffering. Brain research pointed to the brain's fundamental need for creating and maintaining meaning frameworks in the development of purposeful responses to suffering.

Intradisciplinary and/or interdisciplinary implications: Brain research and the contextualisation thereof in psychology is challenging the notion that the only adequate response to suffering is a practical response. The brain's fundamental need for meaningful frameworks is challenging systematic and practical theology to develop theoretical frameworks to guide, motivate and evaluate the adequacy of a practical response.
\end{abstract}

\section{Inleiding}

Die Oostenrykse psigiater Victor Frankl (1978:86-87), het reeds in die vorige eeu daarop gewys dat die uitdaging by die ervaring of bewuswording van lyding daarin lê dat 'n singewende ingesteldheid ontwikkel moet word wat 'n ruimte skep om die betrokke ervaring betekenisvol binne die geheel van menslike bestaan te integreer. Lyding weens die disoriënterende ervaring wat byvoorbeeld pyn, dood, tragedie, bedreiging, geweld en boosheid bring (Creegan 2013:1-13; Frances 2013:13-18), word maklik beleef as 'n 'tragiese teendeel' wat die mens se diep innerlike wil tot sin, houvas en geborgenheid kan blokkeer (Frankl 1978:84-87; Long 2006:140-141). Hierdie standpunt impliseer dat die 'waarom?'-vraag, soos ook die vraag of die werklikheid ten diepste verstaan kan word as meer as net chaos, en of dit die moeite werd is om weerstand te bied teen die tragiese teendeel, vrae is wat smag na betekenisgewing.

In dié verband kan die ontwikkeling van teologiese teodiseë beskou word as pogings om teoretiese betekenisraamwerke daar te stel wat 'n ruimte bied om die ervaring van lyding betekenisvol te integreer. Hierdie pogings is egter die afgelope paar jare sterk bevraagteken (Dueck 2011; Scott 2011; Simpson 2009; Torr 2012). Kritiek op, byvoorbeeld, die misbruik van taal, veralgemening, morele dilemmas en die ontkenning van die kontekstualiteit van ervaring deur teodiseë, het die fokus verskuif van die ontwikkeling van teoretiese betekenisraamwerke na die belang en noodsaak van die ontwikkeling van praktiese response (Culp 2015:263).

Met Frankl se standpunt as vertrekpunt, sou die vraag gevra kon word of hierdie fokus op die ontwikkeling van praktiese response, as reaksie op die impasse van veral teologiese teodiseë, voldoende is om 'n ruimte te skep waarin die ervaring van lyding betekenisvol binne die geheel van menslike bestaan geïntegreer word?

In hierdie artikel word daar op grond van die navorsing van die neuro- en verwante breinwetenskappe aangetoon dat, alhoewel 'n praktiese respons pastorale moontlikhede bied, dit alleen waarskynlik nie voldoende ruimte skep om die ervaring van lyding betekenisvol binne die geheel van die menslike bestaan te integreer nie (Proulx \& Heine 2006:316). Die aversiewe neurologiese aktiwiteit, wat die ervaring van lyding meebring, noodsaak die ontwikkeling van teoretiese betekenisraamwerke (Boase 2008:449, Stapel \& Noordewier 2009:246). Raamwerke wat 'n ruimte skep vir die brein om 'n diepe houvas - 'troos in lewe en sterwe' - te vind, ten einde sinvolle handeling by die ervaring van lyding moontlik te maak (Dingemans 2012:59). Hierdie standpunt beteken dat ondanks al die kritiek op die ontwikkeling van teodiseë, die ontwikkeling van teoretiese betekenisraamwerke nie verby gegaan kan word nie. Om sinvol te kan reageer op die ervaring van lyding vra na beide ' $n$ omvattende wedersydse interaksie tussen praktiese kontekstuele handeling en 'n teoretiese verduideliking wat dié handeling rig en kognitief ondersteun (Culp 2015:263-268). 
Die oogmerk van hierdie studie is om aan te toon dat die behoefte om die ervaring van lyding tot teoretiese betekenis te bring, ten diepste ' $n$ fisiologiese oorsprong in die brein het. Deur gebruik te maak van veral die navorsing van Travis Proulx, van die Universiteit van Tilburg, Nederland (2006, $2009,2012)$, word die ervaring van lyding as 'n neurologiese proses beskryf in terme van ' $n$ 'betekeniskortsluiting'. Hierop word gebou deur aan te toon dat die betekeniskortsluiting, wat ervaar word as 'n 'aversiewe disoriënterende gevoel van absurditeit' in die brein, alleenlik tot kalmte gebring word deur 'n proses van betekenisskepping en -handhawing (Proulx \& Heine 2006:316). Die palliatiewe (versagtende of verligtende) pogings wat die brein aanwend, word kortliks beskryf om so aan te toon waartoe breinprosesse sal neig ten einde die ervaring van lyding betekenisvol binne die geheel van die menslike bestaan te kan integreer.

\section{Betekenisskepping en -handhawing 'n fundamenteel neurologiese behoefte}

Een van die grootste vrese van die mens is die vrees dat daar nie in gebeurtenisse en ervarings betekenis gevind kan word nie. Stapel en Noordewier (2009) in 'Stop making sense: The ultimate fear' sluit hierby aan:

\begin{abstract}
What happens when people's mortality is primed, or when they feel uncertain, or excluded, or unappreciated, or when people are in a bad mood, or when they have just received negative feedback? What is the common psychological denominator that best describes the psychological state people are in when the self is threatened? As we hope is clear by now, a pure existentialistic perspective would suggest that what all these self-threats have in common is that they increase the need for meaning, sense, and structure. (Stapel \& Noordewier 2009:246)
\end{abstract}

Resente ontwikkelings in die neuro- en verwante wetenskappe (Proulx 2012:648-649) wys daarop dat dié fundamentele behoefte nie maar net 'n bloot eksistensiële of sielkundige behoefte is nie, maar dat dit ten diepste 'n fisiologiese oorsprong het. Die biologies evolusionêre ontwikkeling van die menslike brein en die gepaardgaande neurologiese funksionering hiervan maak dit moontlik vir die mens om aandag te kan fokus op, en ook moontlikhede te skep vir die kodering en herinnering van ervarings. Die neurologiese samestelling van die brein skep die vermoë vir die voorspelling en beheer van interne en eksterne omgewings en help om die tragedies en traumas van die lewe te hanteer deur teleologies bevestigende konsepte te kan ontwikkel. Dié vermoë skep ook die moontlikhede vir die ontwikkeling en oordrag van kultuur en die moontlikhede om die dood 'simbolies te kul' deur betekenis te vind in die blywende waardes wat die kultuur voorsien (Proulx \& Heine 2006:311-312).

Dit is hierdie biologiese ontwikkeling en die gepaardgaande neurologiese moontlikhede van die brein wat dit noodsaaklik maak vir die brein om die omringende wêreld saam te snoer in 'n omvattende, interpretatiewe sisteem (betekenisraamwerk), wat beide gevoelsmatige, asook beeldende en begripsmatige fasette het. Die breinstruktuur en -prosesse wil orden en sin gee aan ervarings, ten einde 'n gevoel van houvas te ontwikkel (Dingemans 2012:58).

Menslike wesens is komplekse kognitiewe sisteme. Die brein, as die sentrum van die prosessering van impulse, is 'n relasionele struktuur wat op gedeeltelike wyse ingebed is in die begrensing van die fisieke liggaam en tog ook transenderend omgaan met die ontmoeting van die ander. In teenstelling met blote fisieke objekte, wat 'n 'wese in sigself het', is menslike sisteme altyd besig om in die ontmoeting van die omgewing, die ander of die self, die identiteit van die interaksie of ontmoeting te definieer (Dingemans 2012:14-18).

Die brein 'soek' na koherente verhoudings met die eksterne wêreld, met die innerlike self en met die self in verhouding tot die eksterne wêreld. In hierdie soeke is die verhouding tussen die self en die eksterne wêreld waarskynlik die belangrikste. Die brein is daarop gerig om betekenis te konstrueer deur voortdurend te reageer op die omgewing in ooreenstemming met uniek begrensde strukture. Dit beteken dat die ervaring van betekenis die resultaat is van 'n interaktiewe perspektief wat te doen het met die individu(e) se unieke band met die omgewing verhoudings, begrensdheid, geskiedenis en evolusie. As sodanig verteenwoordig die neurologiese proses van betekenisskepping dan 'n poging om die werklikheid tot bekende te bring deur dit in ' $n$ betekenisraamwerk saam te snoer sodat sinvolle aksie hierin moontlik word (Proulx \& Heine 2006:311-312).

Dié proses, waardeur gebeurlikheid en ervaring tot iets betekenisvols getransendeer word, is 'n onwillekeurige en outomatiese proses van die brein wat vanaf geboorte regdeur die hele lewe op spontane wyse gebeur. Die brein is konstant besig om intuïtief of op bewustelike wyse bewussynsmatige beelde te ontwikkel of te versamel van wat beskou word as die verwagte relasies waarin dinge tot mekaar staan (Moser \& Schroder 2012:367). Op outomatiese wyse word die ervarings en informasie wat deur die sintuie ontvang word, geëvalueer ten einde te ontdek wat die oorsaak van hierdie ervarings of informasie is en of hierdie ervarings of informasie relevant en betekenisvol vir die self is. Patrone en relasies word ontdek en onderskei, terwyl die koherensie en belang van dinge raakgesien of geskep word. Die doel hiervan is om die natuurlike werklikheid, die self en die verhouding tussen die self en die natuurlike werklikheid tot 'bekende' te bring en om dan hierdie 'bekende' te handhaaf.

Wanneer 'n relasionele raamwerk ofte wel 'n betekenisraamwerk geskep is, word dit toegepas op daaropvolgende ervarings met die verwagting dat hierdie verwagte relasie sal konformeer tot vorige relasies. Dit is hierdie verwagtingsaspek van betekenisgewing wat aan mense die gevoel gee dat hulle hul omgewing kan voorspel en beheer. Verwagting maak dit moontlik om ervarings as bekend of gewoon te ervaar (byvoorbeeld sneeu word nie net maar geassosieer met koud nie, daar word ook verwag dat die 
sneeu koud sal wees), en veroorsaak die moontlikheid dat die fundamentele behoefte vervul word om geborge te voel, te beheer en te voorspel sodat die mens die ervaring het dat die lewe in die algemeen sin maak (Heine, Proulx \& Vohs 2006: 90-91; Proulx \& Heine 2009:1126, Proulx \& Inzlicht 2012:318).

Hierdie proses van betekenisgewing word gemotiveer deur 'n algemeen menslike impuls wat gesetel is in die brein, naamlik die behoefte om die sin van simboliese eenheid ('bekende') te ontwikkel en te bewaar. Proulx en Heine (2006) beskryf hierdie simboliese eenheid soos volg:

The echoes of this symbolic unity, can be heard in equilibrium (Piaget, 1960), a need for coherence (Antonovsky, 1979), the unity principle (Epstein, 1981), a need for structure (Neuberg \& Newsom, 1993), cognitive dissonance (Festinger, 1957), a need for cognitive closure (Kruglanski \& Webster, 1996), worldview defense (Pyszczynski, Greenberg \& Solomon) and uncertainty management. (Van den Bos, Poortvliet, Maas, Miedema, \& Van den Ham, 2005). (p. 311)

Die ervaring van simboliese eenheid voldoen aan die primitiewe behoefte om veilig, heel en gesond te wees. Simboliese eenheid verteenwoordig die konsekwente en koherente pogings om relasies daar te stel wat die self en die ander, plekke en gebeure (wat die werklikheid buite die self verteenwoordig) tot 'n eenheid kan saamsnoer. Dit maak dit moontlik om vertroue te vind in die werklikheid, met vertroue daarin te kan handel, en om so 'n ruimte te bied waarbinne 'n ervaring of gebeurlikheid tot sin gebring kan word. Die uitdaging lê daarin om in die proses van kodering en interpretasie, vanuit en in ooreenstemming met die sin van simboliese eenheid, 'n teleologiese dimensie aan 'n ervaring of gebeurlikheid te kan gee. Dit is hierdie ervaring van 'n teleologiese dimensie wat 'n ruimte skep vir die brein om 'n diepe houvas - 'troos in lewe en sterwe' - te vind, en so sinvolle handeling by die ervaring van lyding moontlik te maak (Dingemans 2012:59).

\section{Lyding veroorsaak 'betekeniskortsluiting'}

Heine, Proulx en Vohs (2006:90) toon aan dat wanneer die kodering en die wyse waarop 'n ervaring of gebeurlikheid tot betekenis gebring word, die sin van simboliese eenheid bedreig, die mens dit as lyding ervaar. Pyn, dood, tragedie en boosheid word as lyding beleef omdat hierdie ervarings of gebeurlikhede 'n bedreiging bied vir selfverstaan en dit die ervaring van 'om in beheer te wees' bedreig. Dit bedreig deurdat hierdie ervarings of gebeurlikhede dit 'wat regverdig' is, bevraagteken en dit bedreig omdat dit mense herinner aan hulle mortaliteit.

Lyding is juis lyding wanneer 'n gebeurlikheid of ervaring die sin van simboliese eenheid vernietig of bedreig, omdat daar nie daarin geslaag word om hierdie ervaring of gebeurtenis in ' $n$ teoretiese betekenisraamwerk saam te snoer wat die sin van simboliese eenheid bewaar nie. Wanneer dit gebeur dat die sin van simboliese eenheid nie bewaar word weens mislukte betekenishandhawing, ervaar die brein 'n aversiewe gevoel van disoriëntasie wat neurologies beskryf kan word as 'n betekeniskortsluiting (Proulx \& Inzlicht 2012:320-322).

'n Betekeniskortsluiting word ervaar wanneer 'n ervaring die verwagte relasies kontradikteer van hoe dinge daarna behoort uit te sien (betekenisraamwerk), of wanneer die verstaan van die relasies waarin dinge tot mekaar bestaan, nie daarin slaag om die ervarings of gebeurlikhede te verduidelik nie. 'n Betekeniskortsluiting kan beskryf word as die ervaring van 'die onbekende' of as die ervaring van iets wat betekenis 'ondermyn' of kollektief as die ervaring van die absurde (Proulx \& Heine 2006:318).

As sodanig veroorsaak 'n betekeniskortsluiting eksistensiële onsekerheid wat 'n gevoel van weerloosheid meebring, omdat 'n algemene gevoel van houvas (simboliese eenheid) ontbreek. Die self ervaar eksistensiële onsekerheid omdat die self nie meer kan antisipeer (begrip ontwikkel vir) wat verwag kan word van hierdie gebeure of waarom hierdie gebeure plaasvind nie. Wanneer die sin van simboliese eenheid bedreig word, deur die versteuring van die verwante relasie van sin en orde, gee dit aanleiding tot ervaring van die absurde.

Neurologies verduidelik Proulx (2009:230-234) hierdie ervaring van die absurde deur daarop te wys dat neurokognitiewe strukture in die brein die inkonsekwentheid in betekenisgewing van gebeure of ervarings opmerk en 'n algemene sindroom van neurokognitiewe aktivering met die gepaardgaande aktivering van die simpatiese senuwee stelsel inisieer. Hierdie fisiologiese reaksie gee aanleiding tot 'n negatiewe ('aversiewe') staat van bewuswording. Dit is bewuswording dat die verstaanbaarheid en bekendheid van die ervaring of gebeure vervang of verplaas is. Hierdie ongemaklike, onseker en ondermynende gevoel word beskryf as die ervaring van disekwilibrium, dissonansie, betekenisloosheid en/of onsekerheid, of as die ervaring van absurditeit.

Toegepas op die ervarings van lyding beteken bostaande dat wanneer lyding nie tot betekenis gebring kan word nie, veroorsaak dit 'n betekeniskortsluiting wat aanleiding gee tot die algemene gevoel van absurditeit. Hierdie ervaring van absurditeit by die ervaring van lyding veroorsaak angs, wat gemotiveer word deur 'n dieperliggende eksistensiële angs in die mens - 'die afwesigheid van betekenis' (Stapel \& Noordewier 2009:246).

As eksistensiële angs word hierdie angs beleef as 'dubbeldosis-angs'. Dubbeldosis-angs beteken dat 'n persoon of groep gekonfronteer word deur 'n ervaring waarin daar die moontlikheid bestaan van persoonlike bedreiging en swaarkry wat kan volg op die traumatiese gebeure en dat hierdie ervaring ook in die proses van sin maak, ervaar word as "n verplettering van oortuigings' - die 'wat?', 'waarom?' en 'hoe?' die werklikheid behoort te funksioneer (Proulx \& Inzlicht 2012:322). 
Hierdie angs, wat as 'aversiewe' neurologiese aktiwiteit beleef word, moet vanweë die fundamentele behoefte aan betekenis en die fundamentele vrees vir die afwesigheid van betekenis, tot kalmte gebring word. As kalmerende respons word 'n reeks van palliatiewe strategieë geaktiveer wat daarop gemik is om verlore betekenis terug te vind of betekenis te skep. Vanuit hierdie perspektief kan beweer word dat lyding wat beleef word as 'n betekeniskortsluiting (1) 'n algemeen biologies gebaseerde sindroom bekend as aversiewe opwekking veroorsaak, (2) dit noodsaak kompensasiepogings om dié negatiewe biologiese opwekking te verminder, (3) kompensasiepogings wat bestaan in die vorm van die gebruikmaak van bekende of nuwe teoretiese betekenisraamwerke (Proulx \& Inzlicht 2012:318).

\section{Die uitdaging: 'Om die bedreiging te bemiddel'}

Soos reeds aangetoon, vind mense dit problematies wanneer hulle beroof word van betekenis, of wanneer hulle nie daarin slaag om betekenis te kan skep nie. Hierdie ervaring van fisiologiese dissonansie of disekwilibrium dring die brein om ekwilibrium te ervaar deur betekenis te handhaaf of te vind. Wanneer betekenisraamwerke ontwrig word, ervaar mense die noodsaak om die sin van betekenis te rekonstrueer deur die integrerende betekenisraamwerke waartoe hulle verbind is, te hersien of om hulle te herinterpreteer, of om nuwe betekenisraamwerke te ontwikkel. Navorsing wys dat hoe groter die ontwrigting, hoe dringender is die behoefte om betekenis te vind of te konstrueer in ' $n$ poging om die 'bekende' te herstel (Proulx 2009:230). Stapel en Noordewier (2009) skryf in hierdie verband:

Fortunately, there is empirical evidence for this 'meaningmediates-all-threats' logic. ... Meaning making is the process that describes how people bind together the self-threats that are out there to the psychological states in here. (pp. 246, 247)

\section{Palliatiewe strategieë}

Proulx en Heine (2006:309-318) en Proulx en Inzlicht (2012:325) beskryf hierdie pogings om betekenis te rekonstrueer deur betekenisraamwerke te hersien, te herinterpreteer, of om nuwe betekenisraamwerke te ontwikkel in terme van palliatiewe strategieë wat die brein gebruik. Hulle kies vyf konsepte (genoem die vyf groot A's, naamlik 'Assimilation, Accommodation, Affirmation, Abstraction, Assembly') wat verskillende klasse van pogings om na die bekende terug te keer verteenwoordig: naamlik pogings om die 'bekende' te behou (assimilasie), die bekende te herstel (akkommodasie), terug te keer na die bekende (bevestiging), die bekende te identifiseer, en die bekende te skep (konstruksie).

\section{Assimilasie (Assimilation)}

Assimilasie is die proses waarin die betekenisraamwerk hersien word in 'n poging om ' $n$ sin van die bekende te behou. 'n Algemene reaksie op anomalieë is die assimilasie van anomale ervaring sodat die ervarings nie meer 'n bestaande betekenisraamwerk skend nie. Byvoorbeeld: Slegte dinge gebeur met goeie mense? Dit is seker maar so dat slegte dinge met almal gebeur. Geliefdes gaan dood. Die dood van 'n geliefde moet een of ander doel dien, want niks is toevallig nie en God laat nie toe dat dinge lukraak gebeur nie.

\section{Akkommodasie (Accommodation)}

Akkommodasie is die proses waar die betekenislose ervaring geherinterpreteer of verruim word, deur 'n verklaring of verduideliking te gee wat inpas by bestaande betekenisraamwerke ten einde so die bekende te herstel. Byvoorbeeld: Slegte dinge gebeur met goeie mense? Dit was eintlik'n goeie ding, want dit het hulle sterker gemaak. Soms tref tragedies jou wat jy nie verdien nie.

\section{Bevestiging (Affirmation - fluid compensation)}

Bevestiging is die proses waardeur alternatiewe betekenisraamwerke bevestig word wat soms verband hou en soms geen verband hou nie met die betekenisraamwerk wat geskend word (Proulx \& Heine 2006:312), in 'n poging om terug te keer na die bekende sodat ' $n$ 'sin van simboliese eenheid' weer ervaar kan word. Vloeikompensasie is die deklarasie dat seker bekende oortuigings wat deel is van 'n bestaande betekenisraamwerk gehandhaaf moet word, in die teenwoordigheid van ervarings wat ' $n$ ander verwante betekenisraamwerk skend. Bevestiging verteenwoordig 'n palliatiewe poging om die aversiewe opwekking wat ervaar word wanneer 'n betekenisraamwerk geskend word, te verminder of te vermy. In al hierdie gevalle word 'n betekenisraamwerk bevestig, wat geen algemene inhoud met die ervaring of gebeure deel nie. Hierdie strategie maak dit moontlik om terug te keer na bekende betekenisraamwerke. Byvoorbeeld: Skending van 'n proposisionele 'wat?' lok die bevestiging van 'n morele 'waarom?' uit. Die ervaring van onsin lok die bevestiging van iets anders wat sin maak uit. Proulx en Inzlicht (2012) stel dit soos volg:

And speaking of anxiety-there is no more reliable source of 'potential terror' than reminders of our own mortality. As demonstrated by (hundreds of) studies following from terror management theory (Pyszczynski, et al. 1999) people are strongly affected by reminders of their eventual death, along with everything that death implies for their current existence: the potential pointlessness of their efforts, and the hard limits of what they will be able to understand and experience. Following reminders of this unavoidable, incomprehensible event, people will affirm elements of their cultural worldview to which they are committed-so reliably, in fact, that 'cultural worldview defense' following a mortality salience prime is one of the most replicated experimental effects in the psychological literature (Burke, Martens \& Faucher 2010). (p. 326)

\section{Onttrekking (Abstraction)}

Onttrekking is die proses waardeur versluierde betekenis (bekende) uit 'n reeks nieverwante betekeniskortsluitings onttrek word, in 'n poging om weer met die bekende te identifiseer. Kompensasiestrategieë is nie die enigste wyse waarop ' $n$ betekeniskortsluiting verminder of opgelos word nie. Soms gebeur dit dat daar ' $n$ doelbewuste poging is om betekenis te vind deur met enigiets te identifiseer of patrone te ontdek wat bekend is of ' $n$ gevoel van die bekende gee. 


\section{Konstruksie (Construction)}

Konstruksie is die poging om dele van 'bekendes' en 'onbekendes' te gebruik om 'n nuwe bekende te skep. Soos met assimilasie en akkommodasie kan hierdie konstruksie handelinge verstaan word as pogings waarin daar op 'n direkte of indirekte wyse gepoog word om die betekeniskortsluiting op te los - deur óf die ou bekende te probeer bedek ('masking') of te blokkeer, óf om die konflik of ervaring van absurditeit op te los deur 'n verklaring of verduideliking te gee. In die geval van bevestiging en onttrekking word daar betekenis gesoek deur gebruik te maak van óf 'n bestaande wêreldbeeld óf die eksterne omgewing (Proulx \& Heine 2006:328, 2008:1295).

\section{Die noodsaak om die ervaring van lyding tot betekenis te bring}

In die artikel is aangetoon dat menslike wesens op natuurlike en outomatiese wyse betekenisraamwerke, as die verwagte relasies waarin die self en die wêreld tot mekaar staan, ontwikkel en in stand hou. Dit is 'n fundamentele behoefte by die mens om hierdie raamwerke te bewaar en op koherente en konsekwente wyse te kan reageer op ervaring en gebeure. Dit gebeur soms dat die sin van simboliese eenheid, wat deur hierdie betekenisraamwerke voorsien word, geskend word deur ervarings wat die integriteit van die raamwerke bedreig. Lyding, as die disoriënterende ervaring wat pyn, dood en boosheid meebring, is ervarings wat die potensiaal het om betekenisraamwerke te bedreig. Dit gebeur wanneer daar ' $n$ betekeniskortsluiting ontstaan tussen die ervaring en die 'wat?' of 'waarom?' van die ervaring. Wanneer betekenisraamwerke bedreig of geskend word, gebruik mense palliatiewe strategieë om hierdie bedreiging te verminder of op te klaar sodat hulle sin van simboliese eenheid gehandhaaf kan word en daar met vertroue en bestendigheid - 'troos in lewe en sterwe' gehandel kan word.

Om betekenis te skep of te handhaaf is 'n inherente motiveringsmeganisme wat deel van die evolusionêre ontwikkeling van die mens is. Dit is ' $n$ fundamenteel biologiese en eksistensiële behoefte by die mens wat veroorsaak dat 'n praktiese respons alleen nie die aversie wat deur hierdie ervarings en gebeure opgewek word tot bedaring kan bring nie. Soos reeds genoem, om sinvol te kan reageer op die ervaring van lyding vra na beide 'n omvattende wedersydse interaksie tussen prakties kontekstuele handeling en ' $n$ teoretiese verduideliking wat die handeling rig en kognitief ondersteun (Culp 2015: 263-268). Hierdie 'beide' is nie 'n luukse nie, maar vir die brein inderdaad 'n noodsaaklike.

Die teoretiese vraag 'Waarom?' en daarmee ook die ewe komplekse vraag 'Waarom, God?' gaan nie weg deur met deernisvolle stilte te reageer nie. Alhoewel dit pastorale waarde het, vra die brein ook fundamenteel na 'n teoretiese betekenisraamwerk wat die aversiewe breinprosesse kan kalmeer.

\section{Erkenning}

Die outeur erken hiermee, met dank, die insig en inspirasie van prof. Danie Veldsman van die departement van Dogmatiek en Christelike Etiek, Universiteit van Pretoria, Suid Afrika.

\section{Mededingende belange}

Die outeur verklaar hiermee dat sy geen finansiële of persoonlike verbintenis het met enige party wat haar nadelig of voordelig kon beïnvloed het in die skryf van hierdie artikel nie.

\section{Literatuurverwysings}

Boase, E., 2008, 'Constructing meaning in the face of suffering: Theodicy in Lamentations', Vetus Testamentum 58, 449-468.

Creegan, N.H., 2013, Animal suffering and the problem of evil, Oxford University Press, New York.

Culp, J., 2015, 'Overcoming the limits of theodicy: An interactive reciprocal response to evil', International Journal for Philosophy of Religion 60(1-3), 139-148.

Dingemans, G.D.J., 2012, Het brein geeft te denken: Een nieuwe uitdaging voor iedereen met een frontale hersenkwab, Free Musketeers, Zoetermeer.

Dueck, R., 2011, 'Angry at the God who isn't there: The new atheism as theodicy', Direction 40(1), 4-16.

Frances, B., 2013, Gratuitous suffering and the problem of evil: A comprehensive introduction, Routledge, New York.

Frankl, V., 1978, Waarom lewe ek?, Hollandsch Afrikaansche Uitgevers Maatschappij, Kaapstad.

Heine, S., Proulx, T. \& Vohs, K., 2006, 'The meaning maintenance model: On the coherence of social motivation', Personality \& Social Psychology Review (Lawrence Erlbaum Associates) 10(2), 88-110.

Long, E.T., 2006, 'Suffering and transcendence', International Journal for Philosophy of Religion 60(1-3), 139-148.

Moser, J.S. \& Schroder, H.S., 2012, 'Making sense of it all? Cognitive and behavioral mechanisms needing clarification in the meaning maintenance model', Psychological Inquiry 23(4), 367-373.

Proulx, T. \& Heine, S., 2006, 'Death and black diamonds: Meaning, mortality, and the meaning maintenance model', Psychological Inquiry 17(4), 309-318.

Proulx, T. \& Heine, S., 2008, 'The case of the transmogrifying experimenter: Affirmation of a moral schema following implicit change detection', Psychological Science (Wiley-Blackwell) 19(12), 1294-1300.

Proulx, T. \& Heine, S., 2009, 'Connections from Kafka: Exposure to meaning threats improves implicit learning of an artificial grammar', Psychological Science (WileyBlackwell) 20(9), 1125-1131.

Proulx, T., 2009, 'The feeling of the absurd: Towards an integrative theory of sensemaking', Psychological Inquiry 20(4), 230-234.

Proulx, T. \& Inzlicht, M., 2012, 'The five "A"s of meaning maintenance: Finding meaning in the theories of sense-making', Psychological Inquiry 23(4), 317-335.

Proulx, T., 2012, 'Threat-compensation in social psychology: Is there a core motivation?', Social Cognition 30(6), 643-651.

Scott, M.S.M., 2011, 'Theodicy at the margins: New trajectories for the problem of evil', Theology Today 68(2), 149-152.

Simpson, R., 2009, 'Moral antitheodicy: Prospects and problems', International Journal for Philosophy of Religion 65(3), 153-169.

Stapel, D.A. \& Noordewier, M.K., 2009, 'Stop making sense: The ultimate fear', Psychological Inquiry 20(4), 245-248.

Torr, C.C., 2012, 'A dramatic Pentecostal/Charismatic anti-theodicy: Improvising on a divine performance of lament', unpublished Ph.D. thesis, University of Birmingham, viewed on 08 August 2013, from http://etheses.bham. ac.uk/3681/1/Torr12PhD.pdf 